\title{
Interfacial Fracture Toughness Measurement of New Composite Material SnSb11Cu6/ 20Steel
}

\author{
Yuepeng Gao ${ }^{1}$, Janmei Wang ${ }^{1}$, and Yuyang Liu ${ }^{1}$ \\ ${ }^{1}$ Taiyuan University of Science and Technology
}

November 5, 2020

\begin{abstract}
The interface fracture toughness test of $\mathrm{SnSb} 11 \mathrm{Cu} 6 / 20$ steel is realized by three-point bending experimental technique, interfacial cracks are introduced through the overall bending of the composite panel, and the critical energy release rate of $12.07 \times 103$ $\mathrm{J} / \mathrm{m} 2$ is obtained by calculating the energy released per unit area at the fracture interface. To characterize the stress state of the crack tip, the stress phase angle of the crack tip is calculated using finite element analysis(FEA). At the same time, five sets of FEA experiments are specifically set up to determine the magnitude of the effect of changes in the interface fracture critical load values on the critical energy release rate. The results show that the change in the critical load value affects the critical energy release rate by only $0.08 \%$. And the characterization of the crack tip stress state reveals that the relative strength of the shear stress that drives the interfacial cracking is weaker than that of the positive stress after the crack propagates to a certain length under bending conditions, which also implies that the positive stress is the main reason that drives the interfacial crack to continue propagating when the composite layer is completely fractured.
\end{abstract}

\section{Hosted file}

Manuscript file.pdf available at https://authorea.com/users/373419/articles/491119interfacial-fracture-toughness-measurement-of-new-composite-material-snsb11cu6-20steel
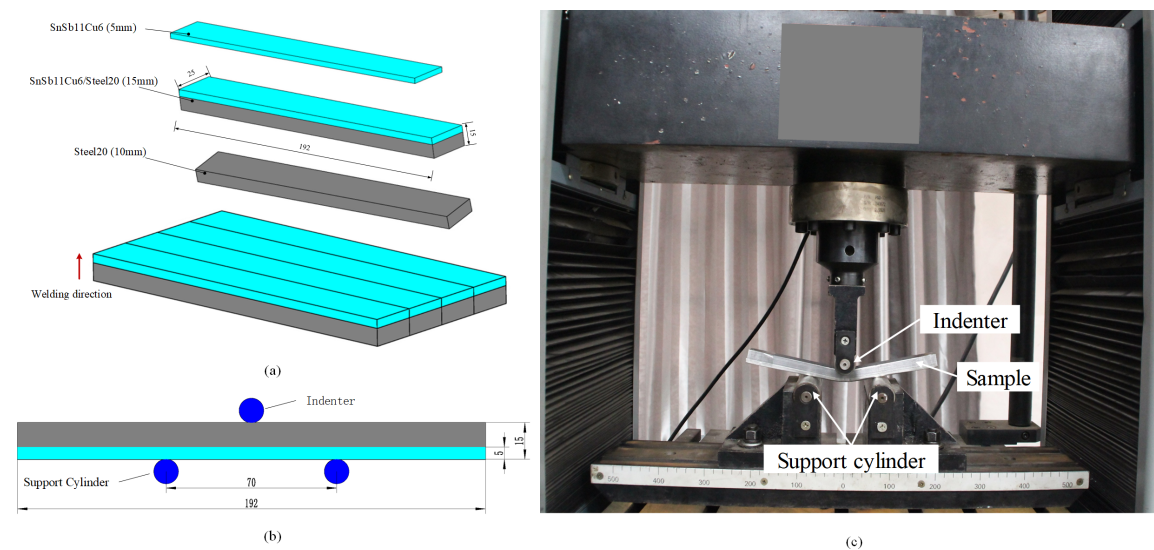

(c)

\section{Hosted file}

Table1.pdf available at https://authorea.com/users/373419/articles/491119-interfacialfracture-toughness-measurement-of-new-composite-material-snsb11cu6-20steel 


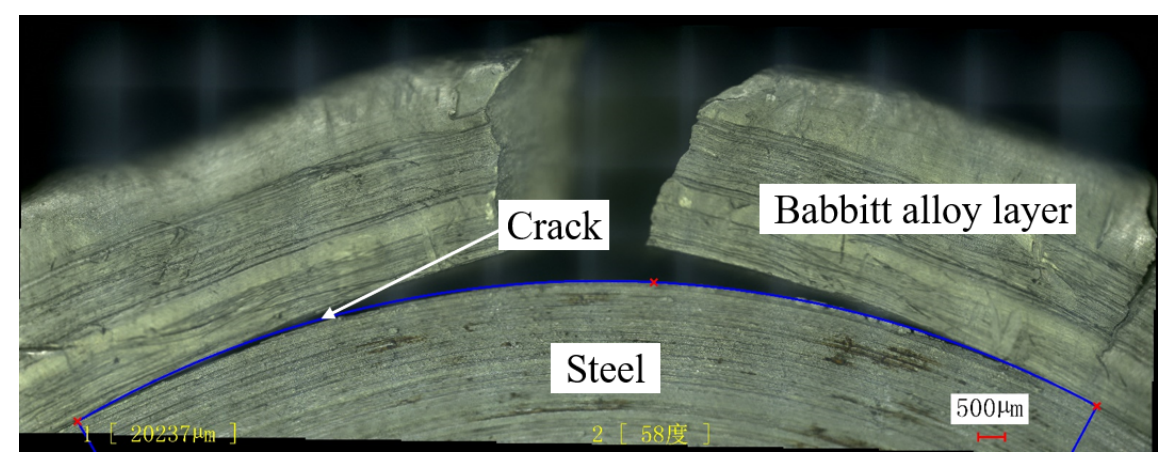

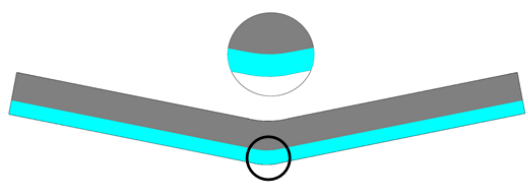

(a) Initial bending

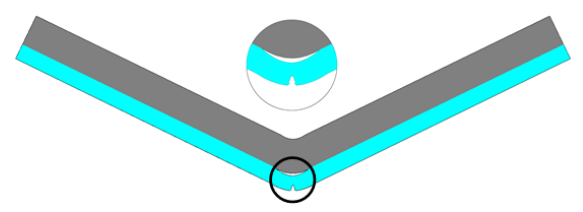

(c) Surface crack

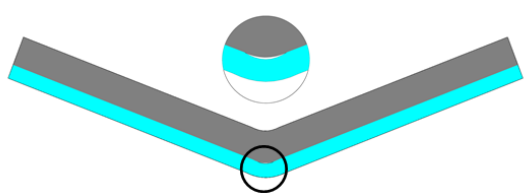

(b) Interface crack

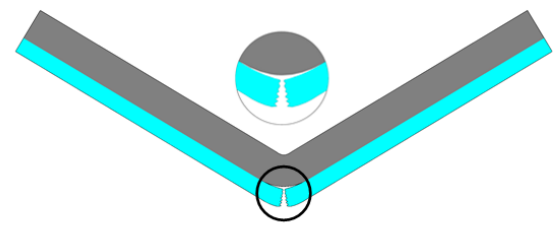

(d) Babbitt layer fracture

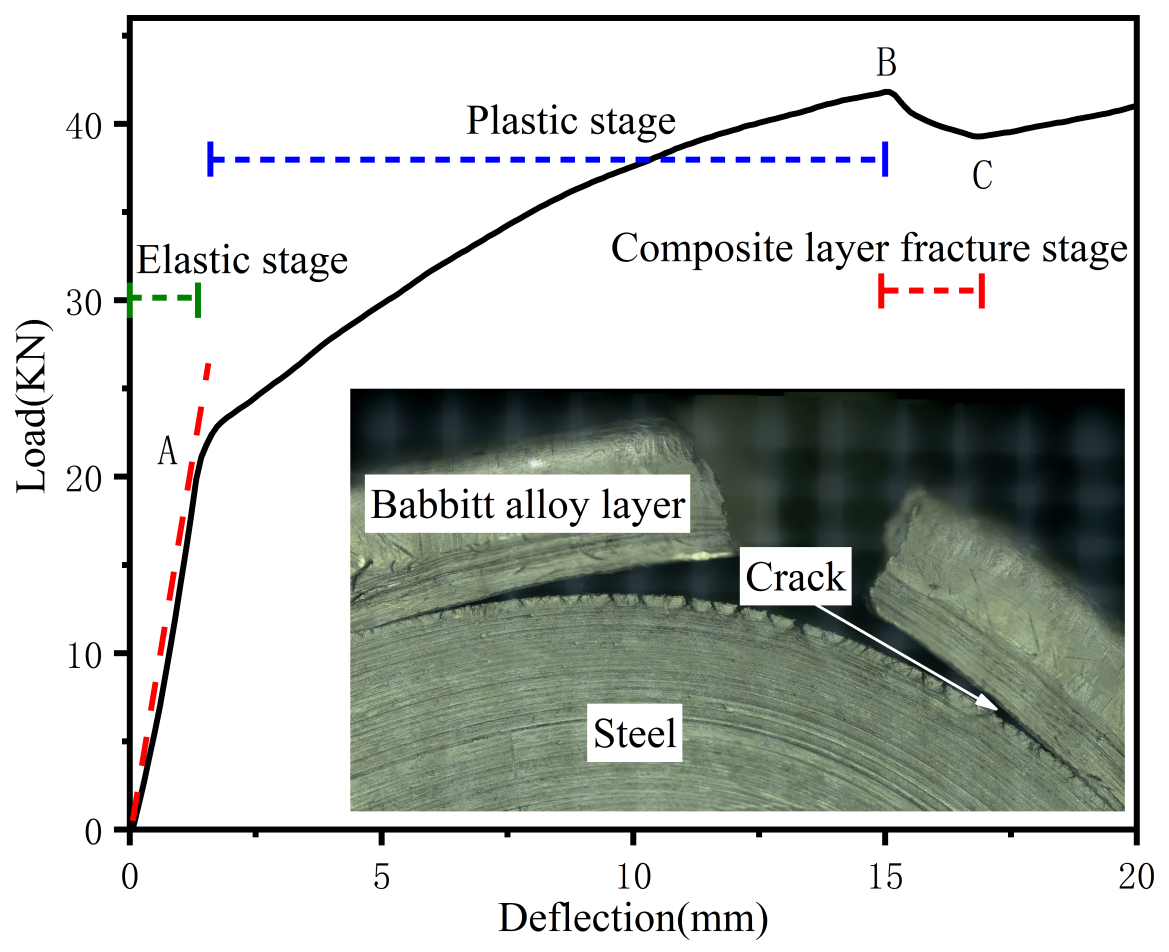



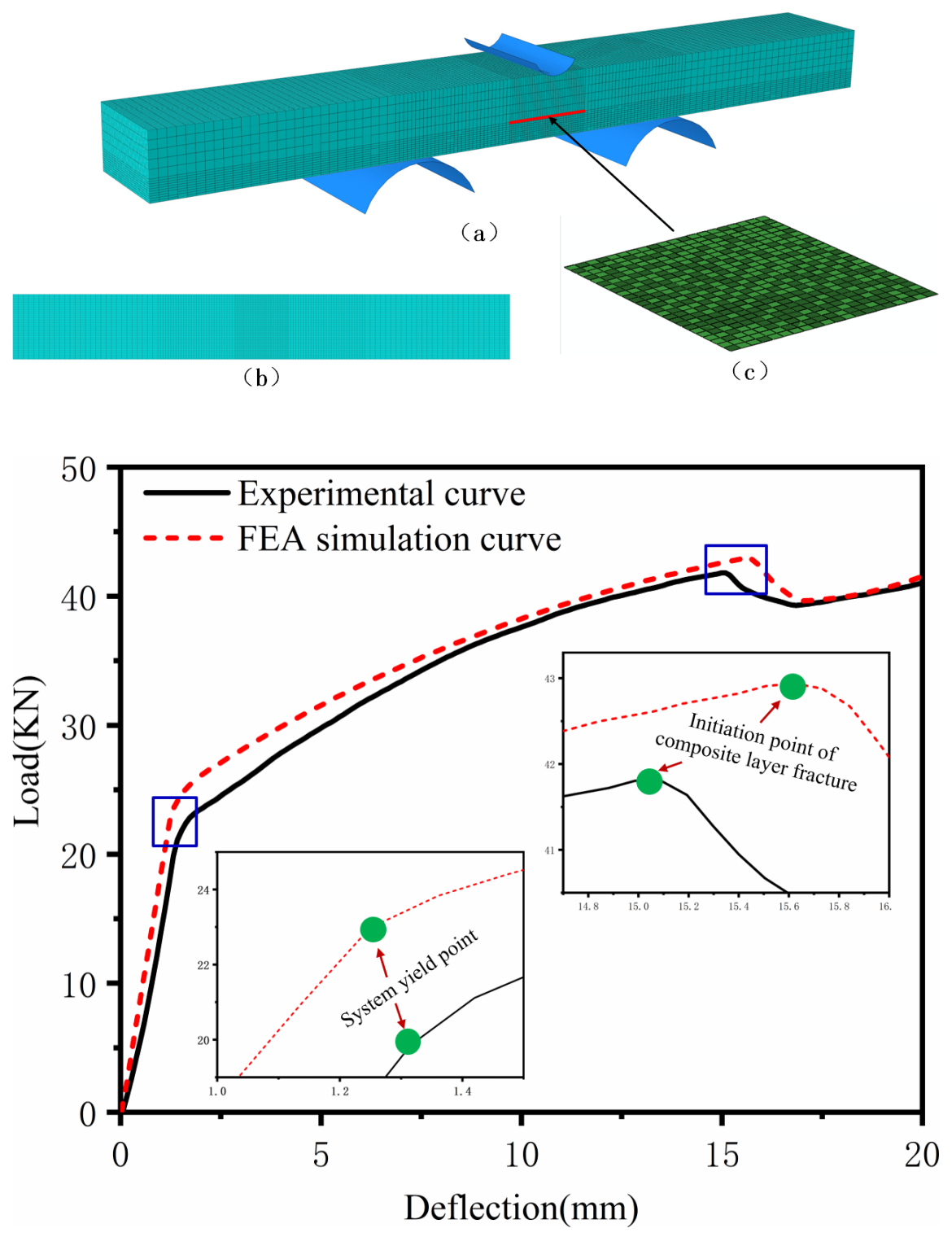


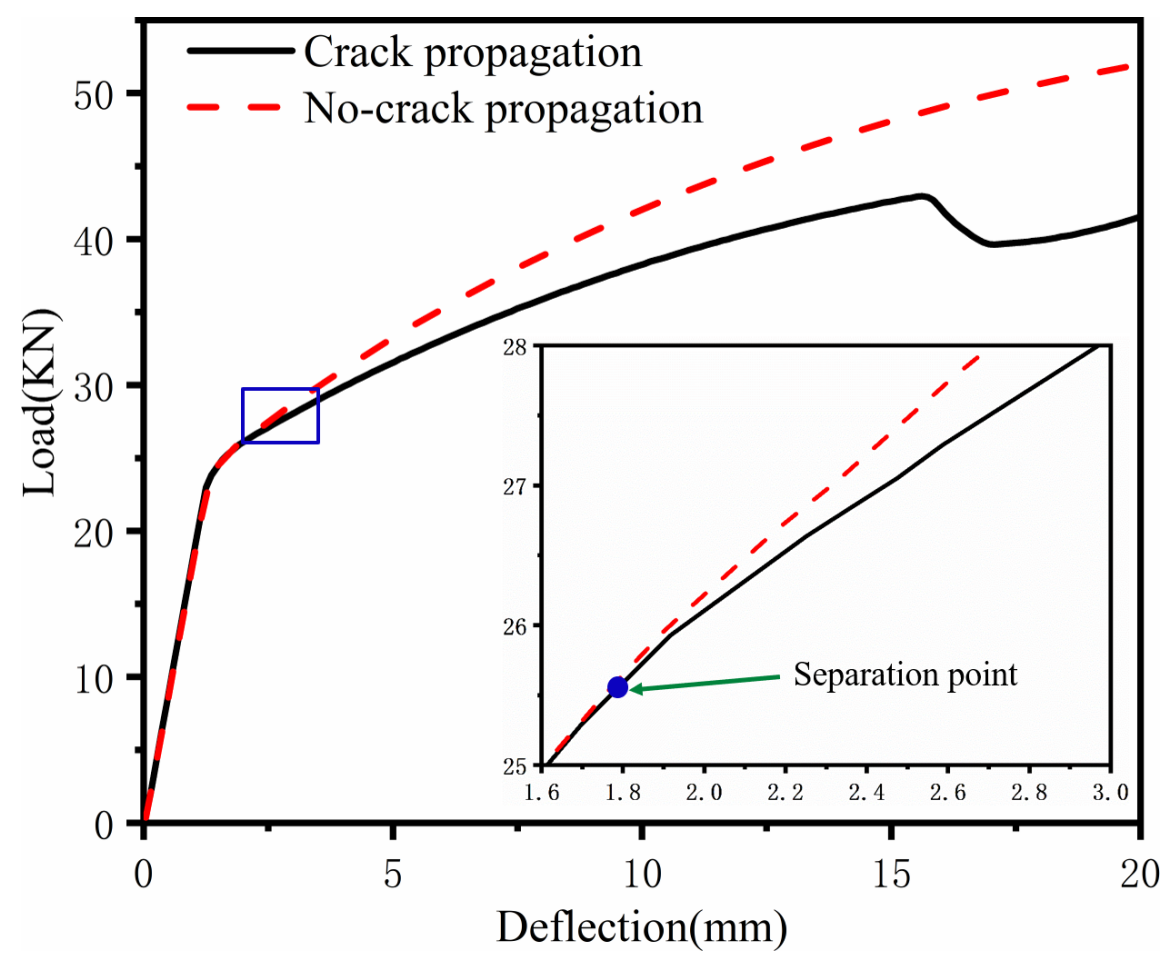



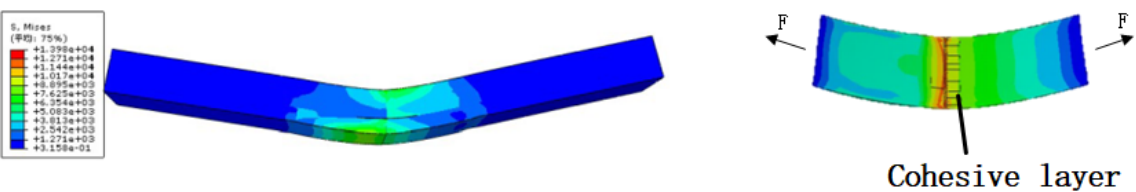

(a) Initial bending
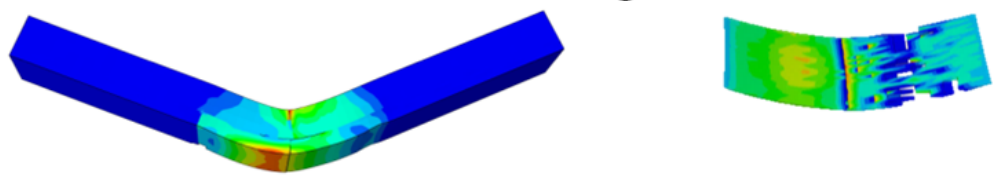

(b) Interface crack initiation
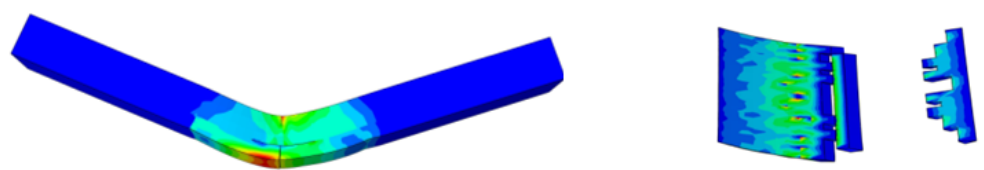

(c) Interface crack propagation and surface crack initiation in composite layer
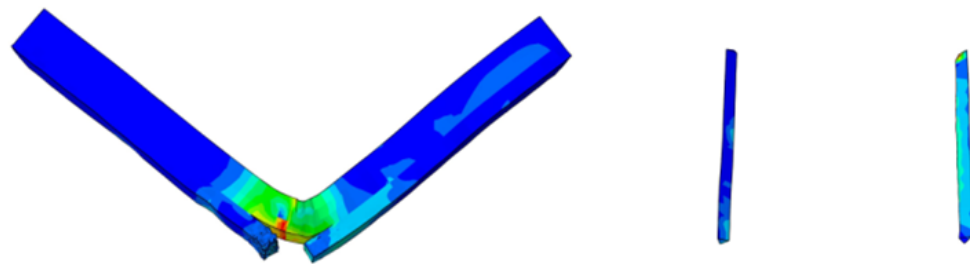

(d) The composite layer breaks and the cohesive layer fails 


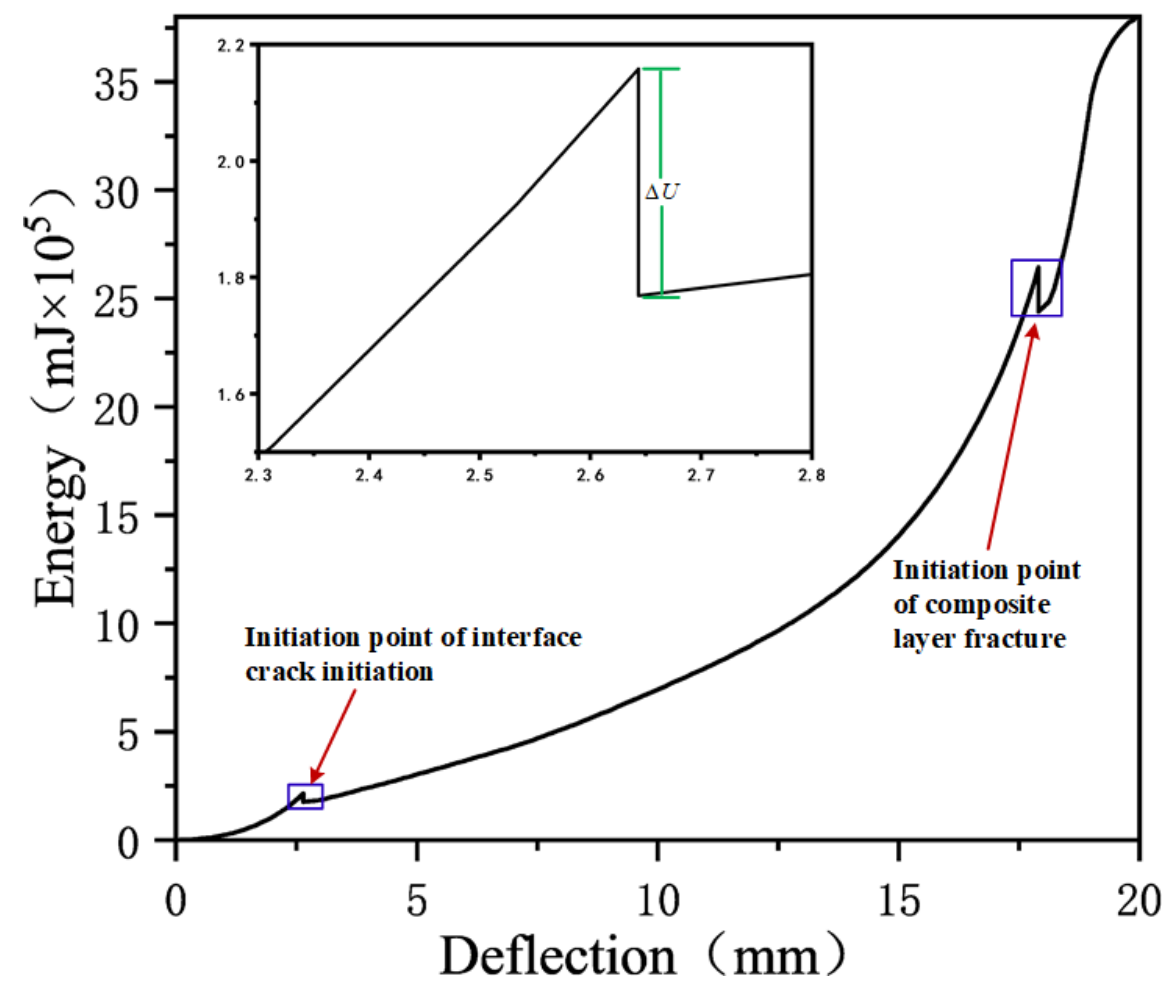

Hosted file

Table2.pdf available at https://authorea.com/users/373419/articles/491119-interfacialfracture-toughness-measurement-of-new-composite-material-snsb11cu6-20steel

\section{Hosted file}

Table3.pdf available at https://authorea.com/users/373419/articles/491119-interfacialfracture-toughness-measurement-of-new-composite-material-snsb11cu6-20steel 